\title{
Retaining and Advancing Librarians of Color
}

\section{Peggy Johnson}

This paper will explore the concept of group mentoring and the possible impact of creating learning communities on retention. It will consider one model, a training institute held biennially at the University of Minnesota, which is directed to early-career librarians of color, and will explore the impact of this institute, which includes group mentoring, on retention and professional contributions.

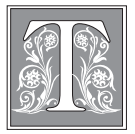

he word "mentor" comes from the Odyssey. Odysseus, before he left to fight in the Trojan War, appointed a guardian for his son, Telemachus. The guardian, whose name was Mentor, was the goddess Athena, disguised as a man. The relationship was based on the idea that Telemachus would emulate Mentor to learn the skills he needed. Because Mentor served as an adviser, coach, counselor, sponsor, advocate, protector, role model, teacher, friend, and nurturer, the term came to be associated with these qualities.

Traditional mentor relationships draw on the acquired wisdom and skills of more senior colleagues to address the support of less experienced colleagues during often difficult transitional stages in their careers. Shea defines mentoring as "a developmental, caring, sharing, and helping relationship where one person invests time, know-how, and effort in enhancing another person's growth, knowledge, and skills, and responds to critical needs in the life of that person in ways that prepare the individual for greater productivity or achievement in the future." ${ }^{11}$

Mentoring serves two functions: those that are career enhancing and those that are psychosocial. Schockett and HarringHidore define vocational or career-related functions as educating, coaching and consulting, sponsoring, providing visibility and exposure, and protection; they describe psychosocial or personal support functions as role modeling, encouraging, counseling, and colleagueship. ${ }^{2}$ Research by Haring reports that mentees cited the psychosocial functions as being the most important to them. ${ }^{3}$ Mentoring can enhance an individual's capacity to make progress and develop skills that will satisfy performance and promotion criteria. Nankivell and Shoolbred published results of a study that showed mentoring served as a valuable tool for developing the careers of library and information professionals. ${ }^{4}$ Simultaneously, mentoring can support an individual's sense of

Peggy Johnson is Associate University Librarian for Access Services in the University of Minnesota Libraries; e-mail: m-john@umn.edu. The first portion of this paper draws on a presentation given in collaboration with Linda DeBeau-Melting, Associate University for Organization Development, University of Minnesota Libraries, at "Keeping Our Faculties III," a conference held at the University of Minnesota, November 18, 2004. 
self-worth and belief in his or her capacity to work effectively in a chosen profession. This takes the form of professional socialization or acculturalization: that is, the development of a professional identity, awareness of professional values, and establishment of professional contacts. Effective mentoring relationships create a deeper understanding of the attitudes and ideology of the profession and-in the context of academic libraries - both librarianship and academe.

Mentors may be assigned by an institution, an individual may seek out a mentor whom he or she admires and who may be in a position to provide advice and support, or a more senior colleague may select a junior colleague in whom he or she sees promise. In the latter two situations, the relationship may be explicitly defined as mentoring or it may be more informal without either partner self-identifying as mentor and mentored partner.

\section{What Is Group Mentoring?}

Group mentoring does not depend on the classical mentor-protégé dyad. It is a relatively new concept, one that is incompletely defined and not well represented in the literature. Broadly, group mentoring can be defined as a function of professional associations in which the career development of members of that professional group is influenced by the group's exertion of social norms and roles. ${ }^{5}$ More narrowly, group mentoring incorporates the stress-reduction benefits of small groups with the advantages of individual mentoring for a cohort of new qualified professionals. ${ }^{6}$ In group mentoring, the functions and roles of mentoring are shared by the group's leaders (or facilitators) and the participants, and carried out over time. A critical component of this definition is that the participants serve as peer mentors to each other, fulfilling the function of mutually supporting and encouraging each other.

Group mentoring shares characteristics with learning communities and communities of practice. The term "learn- ing community" is most often found in education literature. The aim of learning communities is to provide a cohort that offers a level of collegiality and support and that creates a learning environment that fosters development. In higher education, curricular learning communities are classes that are linked or clustered during an academic term, often around an interdisciplinary theme, and enroll a common cohort of students. A variety of approaches are used to build these learning communities, with all intended to restructure the students' time, credit, and learning experiences to build community among students, between students and their teachers, and among faculty members and disciplines.

According to Kofman and Senge, enduring learning communities are grounded in three foundations: a culture based on values; a set of practices for generative conversation; and a capacity to see and work with the community as a system. ${ }^{7}$ Sterling notes that generative conversation in a learning community acts as the "glue to affirm its values and its membership, and infuse it with the energy, imagination, and commitment of the group." ${ }^{8}$ Group mentoring can serve as a learning community.

Communities of practice, a concept promoted by Wenger, focuses more on the corporate sector. ${ }^{9}$ He defines a community of practice as a group of people who share a concern, a set of problems, or a passion about a topic, and who develop their knowledge and expertise in this area by interacting on an ongoing basis. Wenger states that communities of practice develop around things that matter to people. They share a joint enterprise, a mutual engagement that binds them together into a social entity, and a repertoire of communal resources (such as sensibilities, vocabulary, or styles). A community of librarians that have a common perspective by virtue of years in the profession, age, shared ethnicity, subject focus, position responsibilities, home library, other shared perspective 
or experience, or a combination of one or more of these can constitute a community of practice.

Women and minorities in organizational settings often have limited access to or exclusion from communities of practice or informal interaction networks. ${ }^{10}$ Such communities or networks provide instrumental resources that are critical for effective performance and career advancement as well as social support and friendship. ${ }^{11}$ Being excluded, often unconsciously and unintentionally, from these networks can result in both lack of success and a feeling of disenfranchisement and, ultimately, result in the individual leaving a position and the profession. Intentionally creating a group that will provide these resources and opportunities can address these critical needs.

These three concepts - group mentoring, learning communities, and communities of practice - share the premise that personal development is most successful in a shared, social context. Emphasis is on individual development as a broadening of the practitioner's knowledge and skills to cope with change and new initiatives and to achieve flexibility in complex work environments. In this context, personal development in a shared, social context is contrasted with training as assistance in maintaining professional knowledge and skills and with education as preparation for assuming new responsibilities or changing career paths. ${ }^{12}$ Career and personal development are influenced by the group's exertion of social norms and roles as well as the information that is brought to the group. A small and homogenous subset of a larger group (in this case, the library profession) can offer structured, mentoring-based learning in a shared environment as a means of facilitating the successful transition of new librarians of color to successful careers.

\section{Retention}

Retention of qualified and motivated librarians is critical. The library profession is aging; nearly 40 percent of U.S. and Canadian librarians are between the ages of forty-five and fifty-four, and 18 percent are between fifty-five and sixtyfour, with significant retirements over the next ten to fifteen years. ${ }^{13}$ The decline in the number of librarians is compounded by intense market competition for information professionals, which draws them into the corporate sector. Institutions need to protect their future and their investment. Libraries need to approach the challenge of retaining young and qualified librarians intentionally and deliberately. Curan states that libraries need to plan intentionally for who will lead libraries in the future and pay attention to who is presently being trained to ensure continuity into that future. ${ }^{14}$

Simultaneously, libraries face the challenge of recruiting and retaining minority librarians. Only 12.8 percent of professional staff in U.S. Association of Research Libraries (ARL) member libraries belong to one of the four non-Caucasian categories for which ARL keeps records. ${ }^{15}$ The representation is Asian/Pacific Islander -5.8 percent, Black -4.5 percent, Hispanic-2.2 percent, American Indian/ Alaskan Native -.03 percent. ${ }^{16}$ This does not reflect the increasing diversity in the U.S. population. Several professional associations, such as the American Library Association, Medical Library Association, and the Association of Research Libraries, are working to recruit people of color into librarianship. Bonnette has written "of concern to most minority librarians today is not discrimination in hiring, but lack of career development or advancement strategies for minorities. Many early- to mid-career minority librarians struggle against low salaries, lack of professional training, and ultimately, stagnating careers." 17

Mentoring is particularly critical in the retention of minority librarians. Studies show that employees are twice as likely to look elsewhere for employment if their organizations do not offer mentoring. ${ }^{18}$ Balderrama reports that the primary concerns of multicultural and diverse librar- 
ians were recruitment, hiring, retention, and career advancement or promotion. ${ }^{19}$ Howland states that retention and promotion of minority librarians are central to developing a more inclusive profession..$^{20}$ Retention is fostered by opportunities for growth and enrichment (professional development and continuing education), assistance with career advancement, working conditions (especially a collaborative environment), feeling valued, and membership in a peer group. One-on-one mentoring is one way to foster retention. Thomas, in his research, learned that "mentoring was the one shared characteristic of all the people of color who have advanced the furthest; they all shared a strong network of mentors and corporate sponsors who nurtured their professional development." 21 Yet even in those institutions that have formal one-on-one mentoring programs, most often a minority librarian is paired with a member of the majority culture largely because senior minority librarians are not common in most libraries. Libraries recruit librarians of diverse background but expect them to conform to the dominant culture when they arrive. Newly hired librarians can feel isolated, and minority librarians can feel even more isolated, even alienated.

Mor Barak, Cherin, and Berkman report that "interpersonal similarity increases ease of communication, improves predictability of behavior, and fosters relationships of trust and reciprocity. Consequently, we can expect a clear preference for individuals to interact with coworkers who are like themselves." 22 Creating a group mentoring program - in the case of the University of Minnesota, a week-long institute-benefits from drawing together a community that shares ethnic, racial, social, and experiential characteristics. Though initially limited in space and time (one week spent together in one location), the creation of a learning community can become a community of practice that is not bounded by geographic proximity or that extends long beyond the institute's six days.

\section{The University of Minnesota Institute}

The University of Minnesota (UM) Institute for Early Career Librarians from Groups Underrepresented in the Profession was first offered for twenty librarians in the summer of 1998 and was funded by a U.S. Department of Education grant. The libraries offered the institute again in 2000 with support from an Institute of Museum and Library Services grant. Neither agency was prepared to serve as a continuing source of funding. Because of the institutes' value and the positive responses from participants, the libraries chose to continue them without external funding, relying on a combination of funding sources. Beginning with the 2002 institute and continuing, the libraries have transferred some financial responsibility to the participants' home institutions (\$500, plus travel expenses). In 2002, the H.W. Wilson Foundation supported the institute with a $\$ 12,500$ donation. Also, in 2002, the libraries began drawing on an educational endowment that had been given to the University of Minnesota for educating minority librarians.

The impetus behind this institute was the realization that early career librarians of color can feel especially isolated, both because they are joining a white dominated profession and because most of their colleagues are older and more experienced. Even a new librarian who shares the same racial background as the majority of his or her colleagues can feel isolated. The confusion and miscommunication between generations is well documented. ${ }^{23}$ This is compounded by social, economic, ethnic/racial, and age differences. The University of Minnesota Libraries have had a two-year residency program for librarians of color since 1991. With one exception, the libraries have always made two co-terminus appointments. The institute planners saw how beneficial these new librarians found having a peer to be. The planners also heard from UM residents about the isolation and stresses that their colleagues faced at other institutions if they did not have 
an in-house colleague sharing similar experiences.

In response to this need, the institute planners created a one-week institute for librarians of color who were in their first three years of obtaining professional appointments. The institute has had, from the beginning, a twofold focus:

- Institute participants are given a forum for leadership development and increased understanding of themselves and behavior in complex organizations, and presented opportunities to explore practical skills in key areas for librarians. The skills component of the week has changed with each institute as expertise and articulated needs change. In the 2004 institute, skills sessions addressed writing grant proposals, concepts and skills for instructional design, and techniques for outcomes assessment and evaluation. In earlier institutes, new technologies (Web page design, $\mathrm{XML}$, etc.) were part of the curriculum; this segment has been dropped as skills levels increased among the participants.

- In addition, participants gain a community of peers with whom they develop a support network that is intended to continue through their professional careers. The goal of the institute is to equip librarians from underrepresented groups, who are early in their careers, with the knowledge and skills to obtain the positions they seek and to succeed as librarians.

Staff members from the Association of Research Libraries Office of Management Services (OMS) have provided the leadership development component of the institutes. The trainers, Kathryn Deiss and DeEtta Jones, now independent consultants, have extensive experience in designing and delivering training that integrates managerial and leadership concepts with immediately applicable workplace skills. Other components of the curriculum are presented by experts in the university and consultants in the community. Early institutes contained briefer segments presented by UM
Libraries staff. This was changed over time to provide full days on topics, delivered by experienced trainers who received the highest evaluations from participants.

\section{Application Process}

Each participant completes an application. The criteria for participants are:

- Currently employed as an academic librarian, having no more than three years of professional experience.

- Member of an underrepresented racial or ethnic group and a citizen or permanent resident of the United States or Canada. (Racial or ethnic group membership is based on the categories outlined in the U.S. Census, including American Indian or Alaskan Native, Asian, Black or African American, Native Hawaiian or other Pacific Islander, Hispanic or Latino.)

- A master's degree in library science from an ALA-accredited program.

- Interest in pursuing leadership opportunities and positions in academic and research libraries.

- Demonstrate leadership ability or potential.

- Institutional support demonstrated by a letter from the director of the applicant's home institution that supports participation in the institute through the commitment of a $\$ 500$ registration fee and associated travel costs.

Each applicant completes a "Personal Information Sheet" and writes an essay describing, in approximately 500 words, his or her interest in the institute and affirming his or her commitment to participate fully in all aspects of the week's activities. The application packet consists of these two documents, a resume, and a letter from the director of the applicant's home institution. The director confirms support for the individual's participation in the institute (and a commitment to pay the $\$ 500$ registration fee and associated travel costs), and describes his or her demonstrated and potential skills for success in librarianship. 
A three-person review committee composed of former residents and the UM Associate University Librarian for Organization Development review the applications, reviewing each with care. Special attention is given to the application letter and the letter of support from the director of the individual's home library.

The institute now has a strong national reputation, and being selected to attend is considered an honor. The number of participants is now twenty-four; twenty attended the institutes in 1998 and 2000. The institute planners consider this to be the maximum number that can be accommodated, given the format and goals of the institute.

\section{Program Components}

The institute begins with welcome dinner the day of arrival (Saturday) hosted by the libraries, during which participants will meet the Institute faculty, University Libraries staff members and administrators, and key university representatives (deans, provosts, etc.). This starts the week with a clear message that these new librarians are valued and respected. Starting Sunday, participants attend morning and afternoon seminars. Beginning with the 2002 institute, planners have invited one graduate from the previous institute to spend the first two days with the participants. This institute graduate works closely with the leadership development trainers prior to the institute to present part of the initial introduction to the institute and to be a fully engaged facilitator. Having a former institute participant speak to and spend time with the new cohort has a powerful impact and provides one type of role model and a potential mentor.

Participants are given opportunities for networking and extracurricular activities that can build a sense of community. Each is welcomed at the airport upon arrival by a UM librarian and escorted to the hotel. This local host is available all week to answer questions and serve as a general resource. Participants attend a midweek evening reception with University of Minnesota Libraries staff members. A concluding Friday evening dinner with the University Librarian serves to recognize participants and their completion of the program-again stressing their importance and their value to the profession. They are given certificates, and photos are taken as the certificates are distributed. The farewell event is always exciting and often emotional as participants talk about the impact the week has had and as they say goodbye to new friends.

Each participant is asked to identify a mentor at his or her home institution. This person receives the same preinstitute readings as the participant along with a letter explaining his or her role, which is primarily to discuss the readings before the institute and to serve as a local resource after the institute, helping the participant to process the experience and to begin to apply what has been explored.

Participants are provided housing in a hotel adjacent to campus for the seven nights of the institute. Hotel rooms are shared (two to a room); private rooms are available with additional cost absorbed by the individual. Sharing a room is encouraged as part of the community-building experience. Grant funding for the first institute covered all expenses. In the second and third years, participants' home institutions were asked to pay a $\$ 500$ fee. Beginning with 2004, participants (or their home institutions) were also responsible for travel arrangements and expenses, meals with the exception of banquets and lunches, and local transportation during the institute.

\section{Creating a Community}

A critical element of the institute is creating a sense of community. As soon as a cohort is selected and prior to the institute, institute planners establish an electronic discussion list. Participants introduce themselves via the list. It is the primary vehicle for distribution of logistical information. Participants are encouraged to post questions and comments to the list. 
Having this in place before the institute serves to increase the excitement and also the comfort level of participants.

Often these early-career librarians have not participated in professional development opportunities, are inexperienced travelers, uncertain about expectations, and generally nervous. The opportunity to begin to know each other "virtually" begins to create a community before they arrive. The electronic discussion list continues after the institute. Each cohort is provided its own list until the participants for the next institute are selected. At that point, the previous cohort is added to the all-participants list (now a cohort of eighty-eight). Because the local planning committee is on the list, institute planners know the level and duration of continuing conversation. Participants make arrangements to meet at national conferences, solicit colleagues to work on research projects and develop presentations and publications, alert each other about interesting resources and job opportunities, share personal and professional news, and engage in sometimes heated and lengthy discussions about topics that pique their interest. Institute planners and trainers are often invited to meet socially at national conferences with cohorts of the various institutes.

\section{Institute Evaluation}

Each institute has two formal evaluation components. Participants complete an evaluation form at the conclusion of the institute that focuses on content, logistics, and presentation of the sessions. This first evaluation is critical in guiding development of the next institute (content and logistical arrangements). A second evaluation is conducted twelve months after the institute. This final evaluation asks the participant to reflect on how the institute-the content of the sessions and the community that developed-has influenced him or her over the last year. These evaluations are powerful statements of the importance the institute has had and continues to have in the personal and professional lives of the participants. The following representative responses are from participants in previous institutes, when surveyed one year after attending.

Meeting other minority library professionals with differing interests and the will to make their plans come true is priceless.

I think the institute has influenced my career development in the past year. The institute created a wonderful environment for getting to know other new librarians, some of whom I've met up with at a couple of conferences since then. Also, I feel the leadership training game me a lot of confidence in my potential and helped me to better understand how I best work, what role I pay in the workplace, my work values, etc. It gave me a lot to think about in terms of what I want to contribute to the profession and where I'd like to go with my career.

I was highly touched and motivated by our institute leaders, from our facilitators to all those who made the institute possible. Their leadership, guidance, and commitment to early career librarians and librarianship are a great example to all librarians. Their spirit has fueled my enthusiasm and love for librarianship.

I feel like a community was created at the Minnesota institute. If I need to contact any of my classmates for anything, they'll be there to help, as I would be for them. It's great to have this community born from a deeply shared experience.

I have gained a better understanding of the library as an organization and better understanding of my own leadership still. I can grasp the bigger picture and determine what's 
really important. I've also become more careful about making assumptions about people's behaviors and their motivations.

I have become more confident in being part of a big, sometimes lonely, organization. Prior to the institute, I was still trying to get beyond the timidity of being the "new librarian." I am much more involved in issues outside my department, and actively pursing a role in professional organizations and taking positions of leadership in them. In general, I feel more part of my organization and see it as the launching pad for achieving goals that became more firmly shaped since [the] Minnesota [institute].

\section{Institute Impact over Time}

In the spring and summer of 2005, the author conducted a brief e-mail survey of 1998, 2000, 2002, and 2004 institute participants (appendix). The purpose was to determine if participants had remained in the field of librarianship, if they felt the institutes had a positive influence on their careers (as evidenced in new positions, promotions, or positions with greater responsibility), and if they had collaborated with institute colleagues in professional activities. This latter section of the survey sought to determine if collaborative projects and contributions to the profession resulted from relationships developed through the institutes (within the community of practice). The research reported here is not scientifically rigorous because it does not compare institute participants with a control group of librarians of color who did not attend the institutes, and data represent only institute participants who responded to the survey. The author was particularly interested in participants' perceptions of the institutes' impact.

Response rates (those who responded to an initial and one second e-mail request) were generally high, ranging from 60 percent (1998 institute participants) to 83.3 percent (participants in the most recent institute held in 2004). A total of 66 answered the survey for an overall response rate of 75 percent. Details are presented in table 1. One should not be surprised that participants in the most recent institute were more likely to respond since they were the most connected in time to their experiences.

The two primary goals of the institutes have been retention of librarians of color in the profession and creating communities of practice for mutual support and development. Data suggest that librarians who attend the institutes are remaining in the profession, with some attrition over time; see table 2 for these data, as well as those discussed in the following paragraphs. Most recent participants are all still working in libraries, while 83.3 percent of those who attended the first institute in 1998 remain working in libraries. This is a positive finding, though-because the data do not reflect a control group-one cannot draw the conclusion that attending the institute and being part of a cohort directly correlates with retention. Nevertheless, this is good news for the profession with more than 90 percent of total respondents remaining at work in libraries.

Participants who attended the first institute are more likely to have changed jobs since they attended the institute in 1998 than those who attended in subsequent years. Frequency of chang- 
Retaining and Advancing Librarians of Color 413

\begin{tabular}{|c|c|c|c|c|c|c|c|c|c|c|}
\hline \multicolumn{11}{|c|}{$\begin{array}{c}\text { TABLE } 2 \\
\text { Survey Results }\end{array}$} \\
\hline \multirow{2}{*}{$\begin{array}{l}\text { Year of } \\
\text { Institute } \\
\text { 1. Currently work in } \\
\text { a library }\end{array}$} & \multicolumn{2}{|c|}{$\begin{array}{c}2004 \\
n=20\end{array}$} & \multicolumn{2}{|c|}{$\begin{array}{c}\mathbf{2 0 0 2} \\
\mathrm{n}=18\end{array}$} & \multicolumn{2}{|c|}{$\begin{array}{c}\mathbf{2 0 0 0} \\
\mathrm{n}=16\end{array}$} & \multicolumn{2}{|c|}{$\begin{array}{c}1998 \\
\mathrm{n}=12\end{array}$} & \multicolumn{2}{|c|}{$\begin{array}{c}\text { Total } \\
\mathrm{n}=66\end{array}$} \\
\hline & 20 & $100.0 \%$ & 16 & $88.9 \%$ & 14 & $87.5 \%$ & 10 & $83.3 \%$ & 60 & $90.9 \%$ \\
\hline $\begin{array}{l}\text { 2. Changed job since } \\
\text { attending institute }\end{array}$ & 4 & $20.0 \%$ & 10 & $55.6 \%$ & 9 & $87.5 \%$ & 10 & $83.3 \%$ & 33 & $50.0 \%$ \\
\hline $\begin{array}{l}\text { 3. Attending institute } \\
\text { contributed to gaining } \\
\text { new position }\end{array}$ & 2 & $50.0 \%$ & 2 & $20.0 \%$ & 5 & $55.6 \%$ & 6 & $60.0 \%$ & 15 & $45.5 \%$ \\
\hline $\begin{array}{l}\text { 4. Been promoted/ } \\
\text { given greater } \\
\text { responsibility }\end{array}$ & 4 & $20.0 \%$ & 12 & $66.7 \%$ & 13 & $81.3 \%$ & 10 & $83.3 \%$ & 39 & $59.1 \%$ \\
\hline $\begin{array}{l}\text { 5. Attending institute } \\
\text { contributed to } \\
\text { promotion/increased } \\
\text { responsibilities }\end{array}$ & 4 & $100.0 \%$ & 4 & $33.3 \%$ & 8 & $61.5 \%$ & 6 & $60.0 \%$ & 22 & $56.4 \%$ \\
\hline $\begin{array}{l}\text { 6. Collaborated on a } \\
\text { research project }\end{array}$ & 4 & $20.0 \%$ & 6 & $33.3 \%$ & 1 & $6.3 \%$ & 1 & $8.3 \%$ & 12 & $20.0 \%$ \\
\hline $\begin{array}{l}\text { 7. Collaborated to } \\
\text { give a presentation } \\
\text { at a professional } \\
\text { meeting }\end{array}$ & 3 & $15.0 \%$ & 5 & $27.8 \%$ & 2 & $12.5 \%$ & 7 & $58.3 \%$ & 17 & $25.8 \%$ \\
\hline $\begin{array}{l}\text { 8. Collaborated in } \\
\text { publishing a paper }\end{array}$ & 1 & $5.0 \%$ & 2 & $11.1 \%$ & 1 & $6.3 \%$ & 3 & $25.0 \%$ & 7 & $10.6 \%$ \\
\hline $\begin{array}{l}\text { 9. Collaborated in } \\
\text { publishing a book }\end{array}$ & 0 & $0.0 \%$ & 1 & $5.6 \%$ & 0 & $0.0 \%$ & 8 & $66.7 \%$ & 9 & $13.6 \%$ \\
\hline
\end{tabular}

ing jobs declines for those who attended the more recent institutes, ranging from a high of 83.3 percent for 1998 participants to a low of 20 percent changing jobs among those who attended the most recent (2004) institute. Again, this seems logical with frequency of job changes correlating with length of time in the profession. Interestingly, those who attended the 1998 institute (the first held) were more likely to credit their participation in the institute for the job change.

Participants were asked if they had been promoted or been given greater responsibility and, if so, whether they felt that attending the institute contributed to these changes. Overall, 59.1 percent of the respondents have been promoted or been given greater responsibility, with the most recent attendees being least likely to report a promotion or increase in responsibility. The highest instances (83.3 percent) of promotion and greater responsibility are found in the respondents from the 1998 institute. This drops down to 20 percent among most recent institute participants. Further research with a control group (minority librarians who have not attended the institute) would be necessary to determine if this is a normal trend over time for minority librarians or with a comparable group of all early-career librarians to determine the frequency with which early-career 
librarians usually are promoted. Slightly more than 56 percent of all respondents who reporting being promoted or given greater responsibility felt that the institute contributed to this change.

One possible indicator of a successful community of practice is the extent to which members of that community collaborate on professional projects - conducting research, giving presentations, and writing papers and books. The final four questions in the survey explore these possible types of collaboration. Respondents were not asked to limit collaborative partners to those who attended the same institute, but to consider all institute attendees as part of their community for purposes of these questions. While the total number of collaborative projects reported (45) seems initially an impressively large number, one must remember that respondents likely are reporting collaboration on the same projects. More meaningful are the percentages by type of project; overall, 20 percent collaborated on research, 25.8 percent collaborated on presentations, 10.6 percent collaborated on papers, and 13.6 percent collaborated on books. While comparative data are not available, this author finds these data meaningful as indicators of the vitality of the community created through the institutes.

Several respondents took the survey as an opportunity to comment on the impact of the institute. A few of their responses follow:

More than anything, I think the institute helped me to meet other librarians of color and talk about issues and challenges we have in common. I'm the only nonwhite librarian at my library, except for the dean. Thanks!

I have been promoted from Assistant Librarian rank to the Associate Librarian rank through the promotion review process. My experiences at the institute played a part in my
promotion-I particularly highlighted it in my promotion dossier. I must add that the institute did shape my career objectives and how I approached them. I was a very new librarian (and a very young one at that!) when I attended the institute and it was very important to my professional and personal growth and confidence.

Attending the institute gave me more confidence to be true to myself and to embrace my strengths, and hopefully analyze and improve upon my weaknesses. I am more confident acting with authority in my current sphere (thanks to the institute), which may have influenced the amount of responsibility I am willing to take on or accept.

The institute had a great impact on me. I have become more confident in being part of a big, sometimes lonely, organization. Prior to the institute, I was still trying to get beyond the timidity of being the "new librarian." I am much more involved in issues outside of my unit, and actively pursuing a role in professional organizations and taking positions of leadership in them. In general, I feel more part of my organization and see it as the launching pad for achieving goals that became more firmly shaped since [the] Minnesota [institute].

As a matter of fact, 95 percent of the subjects [covered in the institute] prepared me for my new position; not only that, many of my colleagues helped me with some issues that I'm facing.

I found the institute to be very supportive of my professional goals as a new librarian, and reinforced my values of why I chose to go into this profession. I've always had a posi- 
tive attitude toward librarianship, but as a new librarian, I sometimes felt I was lacking guidance in how I could improve. The institute offered practical counsel-plus I got so much from talking with other institute participants. I believe firmly in the value of mentorship and I hope that the profession continues to recognize that librarians new to the profession can benefit from this type of opportunity.

The statistical data reported here, as noted above, leave questions unanswered-namely, how do the results compare with other librarians, both minority librarians and the population of all librarians, who are early in their careers? Viewed in isolation, however, the data suggest that those who attended the four institutes believe that the institutes were valuable for personal and professional growth and in creating a supportive community of peers. More than 90 percent of the respondents remain working in libraries. The stories told by attendees (as presented in their statements above) make clear the value they attach to their participation. From the institute planners' perspective, the University of Minnesota
Institutes for Early Career Librarians from Groups Underrepresented in the Profession are achieving their goals.

\section{Conclusion}

This paper began with the concept of mentoring as serving two functions: career advancement and psychosocial support. Cohort mentoring through communities of practice-composed of those with similar experiences, backgrounds, and aspirations - was suggested as a possible tactic to foster retention, especially of minority librarians, who may feel outside the majority culture of most libraries. Small groups can reduce stress, enhance a sense of community, and provide mutual support. A focused curriculum can increase confidence in leadership skills and professional ability. When a small group develops bonds through an intense experience, these connections endure over time and distance. In effect, group members function as peer mentors, advising and encouraging each other, and (often) collaborating on professional activities. The Minnesota institutes offer one model for creating a community of practice, one that is perceived positively by those who have attended them.

\section{Notes}

1. Gordon F. Shea, Mentoring: Helping Employees Reach Their Full Potential. (New York: American Management Association, 1994), 13.

2. Melanie R. Schockett and Marilyn J. Haring-Hidore, "Factor Analytic Support for Psychosocial and vocational Mentoring Functions," Psychological Reports 57, no. 2 (1985): 627-30.

3. Marilyn J. Haring, "Foreword from the Field," in New Directions in Mentoring: Creating a Culture of Synergy, ed. Carol A. Mullen and Dale W. Lick (New York: Falmer Press, 1999), xi-xii.

4. Clare Nankivell and Michael Shoolbred, "Mentoring: A Valuable Tool for Career Development," Librarian Career Development 5, no. 3 (1997): 98-107.

5. Kathryn H. Dansky, "The Effect of Group Mentoring on Career Outcomes," Group and Organization Management 21, no. 1 (1996): 5-21.

6. Alan J. Reiman, Dee Bostick, and Judy Lassiter, "Counselor- and Teacher-Led Support Groups for Beginning Teachers: A Cognitive-Developmental Perspective," Elementary School Guidance and Counseling 30, no. 2 (1995), 105-17.

7. Fred Kofman and Peter Senge, "Communities of Commitment: The Heart of Learning Organizations," Organizational Dynamics, 22, no. 2 (1993): 5-23.

8. Mary Sterling, "Building a Community Week by Week," Educational Leadership 56, no. 1 (1998), 66.

9. Etienne Wenger, "Communities of Practice: Learning as a Social System," Systems Thinker 9, no. 5 (1998):1-10.

10. Virginia F. O’Leary and Jeanette R. Ickovics, “Cracking the Glass Ceiling: Overcoming 
Isolation and Discrimination," in Womanpower: Managing in Times of Demographic Turbulence, ed. Uma Sekeran and Frederick T. L. Loeng (Newbury Park, Calif.: Sage, 1992), 7-30.

11. Herminia Ibarra, "Personal Networks of Women and Minorities in Management: A Conceptual Framework," Academy of Management Review 18 (1993): 56-87.

12. E. Stephen Hunt and John F. Azzaretto, Professional Workers as Learners: The Scope, Problems, and Accountability of Continuing Professional Education in the 1990s (Washington, D.C.: U.S. Dept. of Education, 1992).

13. William M. Curran, "Succession: The Next Ones at Bat," College E Research Libraries 64, no. 2 (2003):134-40.

14. Ibid.

15. Martha Kyrillidou and Mark Young, com. and ed., ARL Annual Salary Survey 2004-05 (Washington, D.C.: Association of Research Libraries, 2005), 8.

16. Ibid.

17. Ashley E. Bonnette, "Mentoring Minority Librarians up the Career Ladders," Library Administration \& Management 18, no. 3 (Summer 2004): 134.

18. Michael Hickins, "The Silver Solution: Coaxing Former Employees out of Retirement," HR Focus 76, no. 5 (1999): 1, 14-15.

19. Sandra Rios Balderrama, "This Trend Called Diversity," Library Trends 49, no. 1 (Summer 2000): 194-214.

20. Joan Howland, "Beyond Recruitment: Retention and Promotion Strategies to Ensure Diversity and Success," Library Administration and Management 13, no. 1 (Winter 1999): 4-14.

21. David A. Thomas, "The Truth about Mentoring Minorities: Race Matters," Harvard Business Review 79, no. 4 (2001): 98.

22. Michal E. Mor Barak, David A. Cherin, and Sherry Berkman, “Organizational and Personal Dimensions in Diversity Climate: Ethnic and Gender Differences in Employee Perception," Journal of Applied Behavioral Science 34, no. 1 (1998): 88.

23. See, for example, Lynne C. Lancaster, When Generations Collide: Who They Are, Why They Clash, How to Solve the Generational Puzzle at Work (New York: HarperCollins, 2002); and Ron Zemke, Claire Raines, and Bob Filipczak, Generations at Work: Managing the Clash of Veterans, Boomers, Xers, and Nexters in Your Workplace (New York: AMACOM, 2000).

\section{Elegant Solutions for Preservation}

Call for a complete catalog

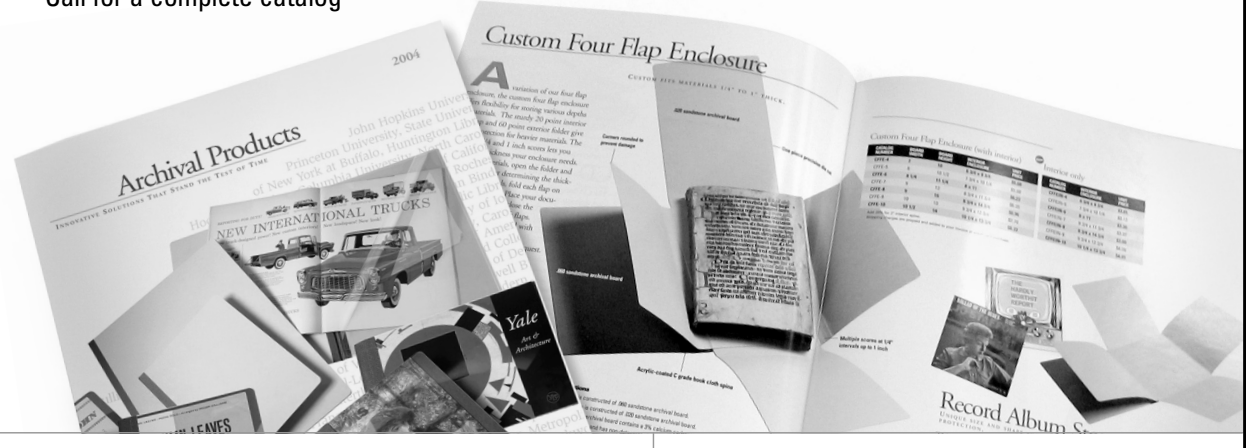

Pamphlet Binders

Music Binders

Archival Folders

Manuscript Folders

Hinge Board Covers

Academy Folders

Newspaper/Map Folders

Polypropylene Sheet \&

Photo Protectors

Conservation \&

Preservation Tapes
Bound Four Flap Enclosures Archival Binders

Archival Boards

Adhesives

Bookkeeper

Century Boxes

Record Album Enclosures

Conservation Cloths

\section{ARCHIVAL PRODUCTS}

P.O. Box 1413 | Des Moines, Iowa 50305-1413

800.526.5640 | Fax 888.220.2397

custserv@archival.com | www.archival.com 


\section{Appendix \\ Survey of Institute Participants}

1. Do you work in a library?

2. Have you changed your job/position since attending the Minnesota institute?

If yes, do you feel that attending the institute contributed to the change?

3. Have you been promoted or moved to a position with greater responsibility since attending the institute?

If yes, do you feel that attending the institute contributed to the change?

4. Have you collaborated with other institute participants (either in your class or from other classes) to:

- Conduct a research project

- Give a presentation at a professional meeting

- Publish a paper

- Publish a book 